DOI: http://doi.org/10.21698/simi.2018.fp32

\title{
OPTIMAL POLICY OF IRRIGATION AND DRAINAGE WELLS SYSTEMS IN AFFECTED AGRICULTURAL LANDS
}

\author{
Victorita Radulescu
}

University Politehnica of Bucharest, Faculty of Energy, Department of Hydraulics, Hydraulic machinery, and Environmental engineering, 313 Splaiul Independentei, district 6, Bucharest, vradul4@gmail.com, Romania

\begin{abstract}
During the last decades, important areas of the Romanian agricultural lands are confronted with some specific problems. In South, due to an inefficient system of irrigation, appears the salting effect. In drought years, entire surfaces are covered with white phosphates (used in excess thirty-forty years ago), destroying the agricultural plant's roots. Contrary, in East, due to improper management of riverbeds, after floods, appear surfaces confronted with excess quantities of water deposition (sometimes even for one entire month), destroying also the agricultural plant's roots. In the present paper, a solution for estimation the necessary level of the water table is presented, assuming a correct correlation between the irrigation during the vegetation period and the drainage during the rest of the year. An agricultural land irrigated by gravity, from the Jiu River basin, is considered, long enough and extended between two emissaries with low topographic incidence. The computational scheme, for unsteady flow with the initial level of groundwater, corresponding to a stationary regime of drainage or injection is adopted. The boundary conditions consist of imposed groundwater levels at areas extremities, in accordance with the known levels of the emissaries. The objective function is defined as a sum of cumulated rates for standard deviations, between the groundwater flow and the water table level, during two years. Some major coefficient's penalties for the waiting time intervals are assumed, to limit the excessive water during the vegetation. A detailed analysis of the underground flow, the numerical model, the obtained results, conclusions, and references are also mentioned.
\end{abstract}

Keywords: agricultural engineering, aquifer management, groundwater flow, irrigation, numerical analysis

\section{Introduction}

The optimum exploitation of agricultural land in the presence of an aquifer polluted by the surface sources requires close monitoring of the groundwater level during the entire year. For the theoretical applications and numerical modeling is considered an agricultural land with low topographic incidence, irrigated by gravity. The aquifer associated with the surface model is assumed as a homogeneous medium, with known permeability. The groundwater is fed by surface sources of pollutant and 


\section{INTERNATIONAL SYMPOSIUM "THE ENVIRONMENT AND THE INDUSTRY", SIMI 2018, PROCEEDINGS BOOK}

drained into an existent emissary, a river, at a lower level, with a known hydrological regime, with a date insurance. It is presented an optimum process of the operating well's control, having as the objective function the cumulative size rates of the deviation between the level of the groundwater and the highest levels maximum acceptable thereof. During two years was made the analysis weighted with high penalty factors, where there is the possibility of exceeding dangerous levels. There are indicated some aspects of the unsteady groundwater flow's problem, for the same case study.

\section{Materials and Methods}

The non-steady flow of the groundwater in an aquifer can be described, with a good approximation, by the Boussinesq equation with partial derivatives. Considering an infinitesimal element of groundwater flow in porous media (Mailhol 2004), the principle of continuity requires the following condition mass balance:

$$
v_{X} \cdot H \cdot d t+q \cdot d x \cdot d t-\left(v_{X} \cdot H\right){ }_{1} d t=n \cdot d H \cdot d x
$$

where: $\mathrm{H}$ - the water table above the impermeable layer from depth, $\mathrm{q}$ - the lateral specific flow rate, $\mathrm{n}$ - the porosity and $\mathrm{x}$ - the horizontal coordinate of a crosssection. Expressing the flow rate through a section 1 with the relation:

$$
\left(v_{X} \cdot H\right)_{1}=v_{X} \cdot H+\frac{\partial}{\partial x}\left(v_{X} \cdot H\right) d x
$$

equation (1) becomes:

$$
-\frac{\partial}{\partial x}\left(v_{x} \cdot H\right)+q=n \cdot \frac{\partial H}{\partial t}
$$

The Darcy law for groundwater flow is equivalent to a dynamic equation, where:

$$
v_{x}=-k \frac{\partial h}{\partial x}
$$

with $\mathrm{k}$ - the Darcy infiltration coefficient and h the level above "datum," a horizontal reference plane. Denoting with I the slope of the impermeable layer may be written the following geometric relationship between the levels $\mathrm{H}$ and $\mathrm{h}$, where $\mathrm{L}$ - is the $\mathrm{x}$ coordinate of the intersection between the impermeable layer and Datum.

$$
h=H-I(L-x)
$$

By eliminating the velocity between relationships 2 and 3 is obtained the system:

$$
\left\{\begin{array}{l}
q+\frac{\partial}{\partial x}\left(k \cdot H \frac{\partial h}{\partial x}\right)=n \frac{\partial H}{\partial t} \\
H=h+I \cdot x-I \cdot L
\end{array}\right.
$$

which is equivalent with the Boussinesq equation:

$$
q+\frac{\partial}{\partial x}\left(k \cdot H\left(\frac{\partial h}{\partial x}-I\right)\right)=n \frac{\partial H}{\partial t}
$$




\section{INTERNATIONAL SYMPOSIUM "THE ENVIRONMENT AND THE INDUSTRY", SIMI 2018, PROCEEDINGS BOOK}

For the unsteady flow, the initial line of the ground water corresponds to the stationary regime with drainage or injection. The boundary conditions consist in levels imposed of the groundwater at the extremities of the analyzed area in accordance with known levels of the emissaries, Figure 1. The specific lateral flow rate $\mathrm{q}$ simulates the regimes of injection if $\mathrm{q}>0$ and the drainage if $\mathrm{q}<0$. It may be imposed an unsteady flow regime of time evolution for the lateral flow rate, with variable limit levels of the emissaries, as consequence of floods or drought periods.

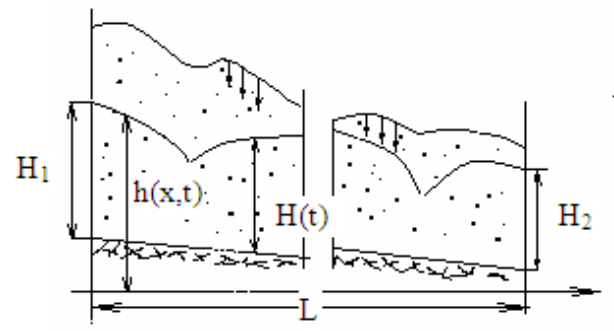

Figure 1. The main parameters for the initial and boundary conditions

The drainage conditions are equivalent to the operating regimes in 2 or 3 rows of wells, modeled with a negative flow rate, known in groups of two adjacent nodes.

The analytical solution of the Equation 5, with the above initial and limit conditions, is quite complex, due to the nonlinearity and complexity of the bi-local limit problem. It is defined as a variable mesh network in which are calculated the values of $\mathrm{H}$ level, with constant time-steps and variable-space steps, both known. To mitigate the non-linearity of the equation is advantageous to introduce a new functions $\mathrm{G}=\mathrm{H}^{2}$, instead of the original function $\mathrm{H}(\mathrm{x}, \mathrm{t})$. The equation (5) becomes:

$$
\frac{\partial^{2} G}{\partial x^{2}}=\frac{n}{k \cdot H} \frac{\partial G}{\partial t}-\frac{2 q}{k}+2 I \frac{\partial H}{\partial x}
$$

It may have meshed:

$$
A_{i} G_{i+1}^{n+1}+B_{i} G_{i}^{n+1}+C_{i} G_{i-1}^{n+1}=D_{i}
$$

where $\mathrm{G}$, the auxiliary dimensionless unknown function, and the coefficients are:

$$
A_{i}=1-\theta_{1} \frac{\alpha}{H_{i}^{\prime}(0)} ; \quad B_{i}=-2-\theta_{1} \frac{2(1-\alpha)}{H_{i}^{\prime}(0)} ; \quad C_{i}=A_{i} \text {; }
$$




\section{INTERNATIONAL SYMPOSIUM "THE ENVIRONMENT AND THE INDUSTRY", SIMI 2018, PROCEEDINGS BOOK}

$$
\begin{aligned}
& D_{i}=-G_{i+1}^{n}+2 G_{i}^{n}-G_{i-1}^{n}-\theta_{1} \frac{\alpha}{{H^{\prime}}_{i}^{(0)}} G_{i+1}^{n}-2 \theta_{1} \frac{1-\alpha}{{H^{\prime}}_{i}^{(0)}} G_{i}^{n}-\theta_{1} \frac{\alpha}{{H^{\prime}}_{i}^{(0)}} G_{i-1}^{n}+ \\
& +2 \theta_{2}\left(H_{i+1}^{\prime}{ }^{(0)}-H_{i-1}^{\prime}{ }^{(0)}\right)-2 \theta_{3}\left(q_{i}{ }^{n}-q_{i}{ }^{n+1}\right)
\end{aligned}
$$

The apostrophe represents the dimensionless terms, a notation of the type $\mathrm{G}^{\mathrm{n}_{i}}$ is the function $\mathrm{G}$ at time $\mathrm{n} \cdot \Delta \mathrm{t}$ in the node $\mathrm{x}_{\mathrm{i}} ; \alpha$ is an over-relaxation factor $\alpha=0.63$, and $\theta_{1}$, $\theta_{2}$ and $\theta_{3}$ are defined as functions

$$
\begin{array}{lll}
\theta_{1}=\left(\xi_{3} \cdot \Delta x^{\prime 2}\right) / \Delta t^{\prime} & \text { where } & \xi_{1}=I \cdot S L / S H \\
\theta_{2}=\xi_{1} \cdot \Delta x^{\prime} & \xi_{2}=S \cdot q \cdot S L^{2} /\left(k \cdot S H^{2}\right) \\
\theta_{3}=\xi_{2} \cdot \Delta x^{\prime 2} & \xi_{3}=n \cdot S L^{2} /(k \cdot S H \cdot S T)
\end{array}
$$

Here: SL, SH, ST are suitable scale factors for the corresponding variables, namely $\mathrm{x}$-coordinate, the level $\mathrm{H}$, the flow rate $\mathrm{q}$, time $\mathrm{T}$, while the upper index (0) represents the mean intermediate values corresponding to the mean values between two successive rows of nodes of type $\mathrm{H}$. The system 7 can be solved with an algorithm tri-diagonal. Connecting the variable $G_{i+1}^{n+1}$ and $G_{i}^{n+1}$ by the equation:

$$
G_{i+1}^{n+1}=E_{i} \cdot G_{i}^{n+1}+F_{i} \text {, where } \mathrm{i}=1 . . \mathrm{M}
$$

is obtained a system of recurrence relations:

$$
E_{i-1}=\frac{C_{i}}{A_{i} E_{i}+B_{i}} ; \quad F_{i-1}=\frac{D_{i}-A_{i} F_{i}}{A_{i} E_{i}+B_{i}}
$$

Admitting as initial conditions the known levels, corresponding to the stationary flow, the calculation starts from the downstream boundary condition:

$$
H_{M}^{n+1}=H_{2}(n \cdot \Delta t)
$$

The groundwater level is equal in this case with to entrance. The condition 11 is identically satisfied if:

$$
E_{M-1}=0, \quad \text { and } \quad F_{M-1}=H_{2}^{2}
$$

The conditions 12 are imposed at any time moment, where $\mathrm{M}$ is the total number of points of type $\mathrm{x}$. Considering the relations (10) is computed $\mathrm{E}_{\mathrm{M}-2}, \mathrm{~F}_{\mathrm{M}-2}$, etc., and finally, $\mathrm{E}_{1}$ and $\mathrm{F}_{1}$. On the other hand, since $H_{1}^{n+1}$ is given in the upstream (the emissary level) can be calculated, $H_{2}^{n+1}, H_{3}^{n+1}$, etc. until the downstream. It is noted that, if the coefficients $\mathrm{A}, \mathrm{B}, \mathrm{C}, \mathrm{D}$ have some terms defined in intermediary time point $(n+1 / 2) \cdot \Delta T$, it is necessary a process of successive approximations, starting from their values at the time $n \cdot t$ and iterated of $n$ times for the same step of the calculation. Due to the non-linearity problem, the calculation 


\section{INTERNATIONAL SYMPOSIUM "THE ENVIRONMENT AND THE INDUSTRY", SIMI 2018, PROCEEDINGS BOOK}

algorithm, even for stationary movement, must begin by indicating the first approximation of the groundwater levels, which is modified during the calculation process. The numerical modeling proves that the concrete form of the groundwater levels as starting function has not a great influence on the convergence rate of the algorithm, so a linear approximation can often be satisfactory (Seteanu 1998).

The case of a stationary bi-local problem has been solved in the same way, as in the case of non-stationary, observing that in this case, the coefficients $\mathrm{A}, \mathrm{B}, \mathrm{C}, \mathrm{D}$, are:

$$
\begin{array}{cc}
A_{i}=\frac{k_{i}}{2(\Delta x)^{2}}\left(1-\frac{I}{2} \frac{\Delta x}{H_{i}}\right) ; & B_{i}=-\frac{4(\Delta x)^{2}}{k_{i}} \\
C_{i}=\frac{k_{i}}{2(\Delta x)^{2}}\left(1+\frac{I}{2} \frac{\Delta x}{H_{i}}\right) ; & D_{i}=-q_{i}
\end{array}
$$

An example of calculation is given hereafter, to determine the infiltration coefficient from sand and clay, using three different methods (Letey 1998, Radulescu 2004).

\section{Hazen Solution}

Noting: A- coefficient pending of measure system, $A=1$ if $k$ is expressed in $\mathrm{m} /$ day;

- c is a coefficient which depends on the clay content of the sand,

- $d_{e}$ - the effective diameter in mm, defined by the granule's diameter lower than $10 \%$ of the entire weight of earth granules,

$$
k=A \cdot c \cdot \tau \cdot d_{e}^{2}
$$

- $\tau$ is a coefficient of temperature correction; $t^{0}$ is the temperature in Celsius degrees

$$
\tau=0,70+0,03 \cdot t^{o}
$$

For the clean sands $c=1000-700$, and for sand with clays $\mathrm{c}=700-500$. Hazen's relationship is applicable to sands with a diameter between $0.1-3 \mathrm{~mm}$. additionally the earth's non-homogeneity coefficient, the ratio $\mathrm{d}_{0} / \mathrm{d}_{\mathrm{e}}$, $\mathrm{d}_{0}$ - the pitch diameter to which $60 \%$ of the granules have a smaller diameter, less $5 \mathrm{~mm}$. If in relation (15) it is considered $\tau=10^{0} \mathrm{C}, \mathrm{c}=860$, k expresses in $\mathrm{m} /$ day, and de in $\mathrm{mm}, k=d_{e}^{2}$

\section{Kozeny Solution}

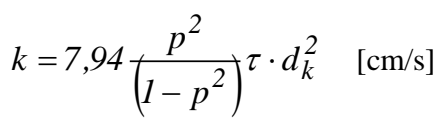

where: $\quad p$ is the porosity coefficient, $\mathrm{d}_{\mathrm{k}}$ the effective diameter $[\mathrm{mm}]$, and $\tau$ is a coefficient for correction of the temperature, presented in Table 1. 
Table 1. Values of temperature coefficient after Kozeny

\begin{tabular}{cccccccccc}
\hline $\mathbf{T}$ & $\boldsymbol{\tau}$ & $\mathbf{T}$ & $\boldsymbol{\tau}$ & $\mathbf{T}$ & $\boldsymbol{\tau}$ & $\mathbf{T}$ & $\boldsymbol{\tau}$ & $\mathbf{T}$ & $\boldsymbol{\tau}$ \\
\hline 0 & 0.588 & 6 & 0.721 & 12 & 0.854 & 18 & 1.000 & 24 & 1.155 \\
1 & 0.612 & 7 & 0.744 & 13 & 0.878 & 19 & 1.025 & 25 & 1.180 \\
2 & 0.635 & 8 & 0.766 & 14 & 0.902 & 20 & 1.052 & 30 & 1.313 \\
3 & 0.656 & 9 & 0.786 & 15 & 0.926 & 21 & 1.080 & 40 & 1.620 \\
4 & 0.676 & 10 & 0.807 & 16 & 0.950 & 22 & 1.107 & 50 & 1.926 \\
5 & 0.698 & 11 & 0.837 & 17 & 0.975 & 23 & 1.131 & 60 & 2.231 \\
\hline
\end{tabular}

\section{E. A. Zamarin Relation}

$$
k=8,07 \frac{p^{2}}{\left(1-p^{2}\right)^{c}} p \cdot \tau \cdot d_{k}^{2} \quad[\mathrm{~cm} / \mathrm{s}]
$$

where $-d_{k}$ is the effective diameter [mm], $c_{p}$ is a coefficient taking account of the land porosity. The coefficient $\tau$ from relation (16) is taken from Table 1 , and the coefficient $\mathrm{c}_{\mathrm{p}}$, from Table 2.

Table 2. Values of coefficient $c_{p}$

\begin{tabular}{cccccccc}
\hline $\mathbf{p} \%$ & $\mathbf{c}_{\mathbf{p}}$ & $\mathbf{p} \%$ & $\mathbf{c}_{\mathbf{p}}$ & $\mathbf{p} \%$ & $\mathbf{c}_{\mathbf{p}}$ & $\mathbf{p} \%$ & $\mathbf{c}_{\mathbf{p}}$ \\
\hline 27 & 0.757 & 32 & 0.632 & 37 & 0.518 & 42 & 0.416 \\
28 & 0.731 & 33 & 0.608 & 38 & 0.497 & 43 & 0.397 \\
29 & 0.706 & 34 & 0.585 & 39 & 0.476 & 44 & 0.378 \\
30 & 0.680 & 35 & 0.562 & 40 & 0.456 & 45 & 0.360 \\
31 & 0.656 & 36 & 0.540 & 41 & 0.435 & 46 & 0.342 \\
\hline
\end{tabular}

\section{Results and Discussion}

To obtain a technically acceptable groundwater level is necessary to impose as a restriction for the top level of the groundwater to be under an imposed value in each node $x$. Furthermore, while the low levels are basically admitted, there are prohibited those nodes exceeding the ground level.

The searching method (Hooke \& Jeeves 2007) has proven effective, generating a series of approximations improved, consisting of searching and extrapolation steps. In the step of exploration, each parameter is examined and is considered solved if the objective function has not increased. The step of extrapolation consists in amplification of the main parameter in the superior direction, but without exploration (Gelting 2013). The convergence and the stopping processes of the optimization scheme correspond in this stage when the exploration steps of the parameters become smaller than certain limit values imposed.

The first choice of the objective function consists in choosing the maximum difference DH, between the groundwater and soil. It is imposed a scheme of minimax, by minimizing the absolute value of the objective function, Figure 2. The obtained errors were quite high, so there were necessary some corrections. To ensure a more suitable position of the groundwater was chosen a new objective 


\section{INTERNATIONAL SYMPOSIUM "THE ENVIRONMENT AND THE INDUSTRY", SIMI 2018, PROCEEDINGS BOOK}

function, defined by the standard deviation between the minimum distances between the two curves. The obtained errors were smaller but still inconclusive, (Seteanu \& Radulescu 2001). To ensure a more balanced position of the groundwater distribution, a new objective function was defined, the standard deviation. The third hypothesis was assumed and the differences between the minimum deviations of the two curves, admits an overcoming of the soil level in some $x$ points, considered discontinuities. After these corrections were obtained smaller errors, which confirms the choice of the objective function. It consists of the cumulating of the absolute values of difference $\mathrm{DH}$, multiplied by a factor of penalties when these differences are positive. The $\mathrm{DS}_{1}$ type areas, Figure 2, are however small, maintaining a balanced appearance of the groundwater.

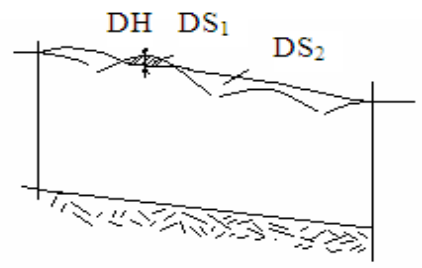

Figure 2. The optimization solution

The modified parameters during the optimization process consist of the spatial coordinates and the drainage rates of the rows of wells. Two numerical cases, with two rows, presented in Figure 3 have been analyzed. The calculation scheme was applied in a sector river of $50 \mathrm{~km}$, between two emissaries with different levels $\mathrm{H}_{1}=70 \mathrm{~m}$ and $\mathrm{H}_{2}=50 \mathrm{~m}$, above the base soil level. The slope for the waterproof layer $\mathrm{I}=4 \cdot 10^{-5}$, the permeability $\mathrm{k}=6 \cdot 10^{-4}$, and porosity $\mathrm{n}=0.38$. It was chosen a number of nodes $\mathrm{x}$, noted $\mathrm{M}=1200$, imposing a uniform flow rate of injection $\mathrm{q}=8 \cdot 10^{-4} \mathrm{~m}^{3} / \mathrm{s} / \mathrm{m}$. The selected porosity coefficients are presented in Table 3 and the optimum parameters for this case in Table 4.
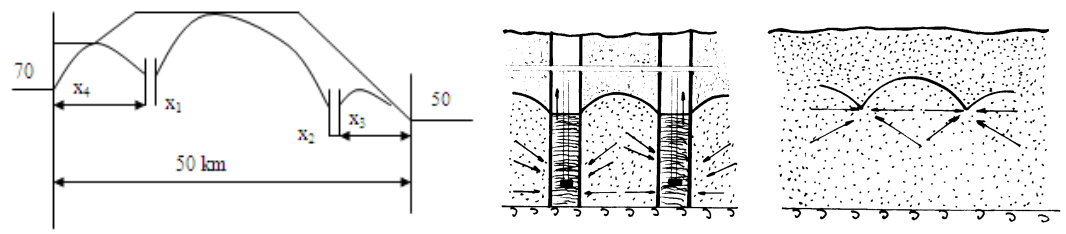

Figure 3. The land scheme with a system with two rows of wells 
Table 3. Values of the porosity coefficient for different soils

\begin{tabular}{cc}
\hline Soil nature & Porosity Coefficient 0 \% \\
\hline Different limestone & $10-17$ \\
\hline Sand with diameter $1 / 2-1 / 4 \mathrm{~mm}$ & 42 \\
\hline Sand with diameter $2 \mathrm{~mm}$ & 36 \\
\hline Gravel diameter around $5 \mathrm{~mm}$ & 37 \\
\hline Earth clay & $46-35$ \\
\hline Peat lands & 81 \\
\hline
\end{tabular}

Table 4. Optimum parameters, scheme with two rows of wells

\begin{tabular}{cc}
\hline $\mathrm{x}_{1}=-2,76 \cdot 10^{-4} \mathrm{~m}^{3} / \mathrm{s} / \mathrm{m}$ & Flow through first wells \\
\hline $\mathrm{x}_{2}=-2,9 \cdot 10^{-4} \mathrm{~m}^{3} / \mathrm{s} / \mathrm{m}$ & Flow through second wells \\
\hline $\mathrm{x}_{3}=11251 \mathrm{~m}$ & Position first wells \\
\hline $\mathrm{x}_{4}=15742 \mathrm{~m}$ & Position second wells \\
\hline
\end{tabular}

Figure 4 presents the scheme with three rows of wells for drainage and the optimum obtained parameters in Table 5. From the analyzed nodes in Table 6 are mentioned a selection of the levels of the groundwater.

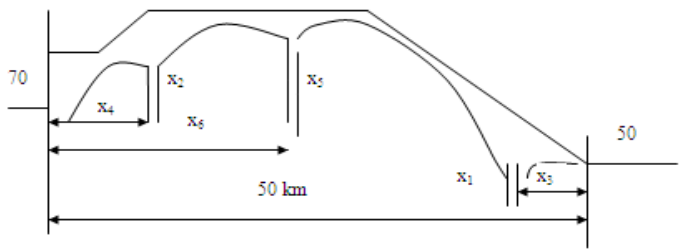

Figure 4. The land scheme with a system with three rows of wells

Table 5. Optimum obtained parameters with three rows of wells

\begin{tabular}{c|c}
\hline $\mathrm{X}_{1}=-1,941 \cdot 10^{-4} \mathrm{~m}^{3} / \mathrm{s} / \mathrm{m}$ & Flow through left wells \\
\hline $\mathrm{X}_{2}=-2,227 \cdot 10^{-4} \mathrm{~m}^{3} / \mathrm{s} / \mathrm{m}$ & Flow through right wells \\
\hline $\mathrm{X}_{5}=-1,803 \cdot 10^{-4} \mathrm{~m}^{3} / \mathrm{s} / \mathrm{m}$ & Flow through central wells \\
\hline $\mathrm{X}_{3}=7688 \mathrm{~m}$ & Position right wells \\
\hline $\mathrm{X}_{4}=10501 \mathrm{~m}$ & Position left wells \\
\hline $\mathrm{X}_{6}=27038 \mathrm{~m}$ & Position central wells \\
\hline
\end{tabular}

Table 6. Obtained levels of groundwater

\begin{tabular}{cccccccccc}
\hline $\mathbf{i}$ & $\mathbf{h}(\mathbf{m})$ & $\mathbf{i}$ & $\mathbf{h}(\mathbf{m})$ & $\mathbf{i}$ & $\mathbf{h}(\mathbf{m})$ & $\mathbf{i}$ & $\mathbf{h}(\mathbf{m})$ & $\mathbf{i}$ & $\mathbf{h}(\mathbf{m})$ \\
\hline 1 & 70.00 & 41 & 83.93 & 81 & 87.70 & 121 & 92.20 & 169 & 73.03 \\
\hline 9 & 76.82 & 49 & 81.36 & 89 & 91.79 & 129 & 88.42 & 177 & 72.42 \\
\hline 17 & 81.33 & 57 & 76.89 & 97 & 94.16 & 137 & 82.79 & 185 & 71.59 \\
\hline 25 & 83.92 & 65 & 73.50 & 105 & 95.00 & 153 & 78.94 & 201 & 68.73 \\
\hline 33 & 84.74 & 73 & 81.82 & 113 & 94.36 & 161 & 76.35 & 1200 & 50.00 \\
\hline
\end{tabular}




\section{INTERNATIONAL SYMPOSIUM "THE ENVIRONMENT AND THE INDUSTRY", SIMI 2018, PROCEEDINGS BOOK}

\section{Conclusions}

This method of calculation may be used to determine the variations of the groundwater in aquifer based on the propagation of waves produced by the floods of emissaries.

The method may be used also in assessing the changes from the groundwater levels, caused by the intensive exploitation of an irrigation-drainage system.

For other practical applications, there is a possibility of combining the calculation scheme proposed with a model of spatial propagation of a front of pollutant in the aquifer. In this case, the penalty coefficients imposed to the objective function vary depending on the upstream, respectively downstream flow, compared with this front. It is possible that in this variant, to be used the favorable influence of the groundwater from the farmland in the unpolluted area, by imposing some gradual restrictions of non-exceeding the maximum levels of pollutant advancement, in the agricultural areas.

\section{References}

Gelting, RJ \& Baloch, M 2013, 'A Systems Analysis of Irrigation Water Quality in Environmental Assessments Related to Foodborne Outbreaks', Aquatic Procedia, vol 1, pp. 130-137.

Letey, J, Dinar, A, Woodring, C \& Oster, D 1998, 'An economic analysis of irrigation systems’, Irrigation Science, vol. 11, no. 1, pp. 37-43

Mailhol, JC, Zaïri, A \& Slatni, A 2004, 'Analysis of irrigation systems and irrigation strategies for durum wheat in Tunisia', Agricultural Water Management, Elsevier, vol. 70, no.1, pp. 19-37.

Method of Hooke and Jeeves, Appendix B. Available from: https://onlinelibrary.wiley.com/doi/pdf/10.1002 /9780470511824.app2. [29 August 2018].

Radulescu, V \& Nistreanu, V 2004, 'Hydraulic Adduction Systems. Fundamentals, Calculassions, Exemples’, Series Hydraulics, Publishing Bren House, Bucharest. In Romanian.

Seteanu, I, Radulescu, V \& Seteanu, S 2001, 'Convective-Diffusive Transport of Pollutants at River Branching (k- $\varepsilon$ Model)', Proceedings Numerical Simulation for Fluid Mechanics and Magnetic Liquids, Orizonturi, University of Timisoara, pp.101-112.

Seteanu, I \& Radulescu, V 1998, 'An Objective Function to Predict Virus Pollution on Saturated Fields', ENVIROSOFT 98, Las Vegas, USA, Comp. Mechanics, Wessex Institute of Technology, pp. 89-93. 